\title{
Comparison of efficacy of fluidotherapy and paraffin bath in hand osteoarthritis: A randomized controlled trial
}

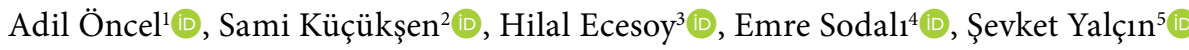 \\ ${ }^{1}$ Department of Physical Medicine and Rehabilitation, Sultanbeyli State Hospital, Istanbul, Turkey \\ ${ }^{2}$ Department of Physical Medicine and Rehabilitation, Necmettin Erbakan University Medical School, Konya, Turkey \\ ${ }^{3}$ Department of Physical Medicine and Rehabilitation, Division of Rheumatology, Necmettin Erbakan University Medical School, Konya, Turkey \\ ${ }^{4}$ Department of Physical Medicine and Rehabilitation, Sabuncuoğlu Training and Research Hospital, Amasya, Turkey \\ ${ }^{5}$ Department of Physical Medicine and Rehabilitation, İpekyolu Hospital, Mardin, Turkey
}

\begin{abstract}
Objectives: This study aims to compare the efficacy of paraffin bath therapy and fluidotherapy on pain, hand muscle strength, functional status, and quality of life (QoL) in patients with hand osteoarthritis (OA).

Patients and methods: This prospective randomized controlled study included 77 patients ( 8 males, 69 females; mean age: $63.1 \pm 10.3$ years; range 39 to 88 years) with primary hand OA who applied between July 2017 and March 2018. The patients were randomized into two groups with the sealed envelope method: Paraffin bath therapy ( $20 \mathrm{~min}$, one session per day, for two weeks) was applied for 36 patients whereas 41 patients received fluidotherapy for the same period. The pain severity of the patients, both at rest and during activities of daily living (ADL) within the last 48 hours was questioned and scored using Visual Analog Scale. Duruöz Hand Index (DHI) was used to evaluate hand functions. Gross grip strength was measured using Jamar dynamometer whereas fine grip strength was measured using pinch meter in three different positions (lateral pinch, tip pinch, and palmar pinch). The 36-Item Short Form (SF-36) was used to analyze the QoL. All measurements were performed before, immediately after, and three months after treatment.

Results: Improvement was observed in pain score at rest and during ADL, DHI scores, gross and fine grip strengths, and SF-36 subscores in both groups after treatment. However, no significant difference was observed between the groups.

Conclusion: Both fluidotherapy and paraffin bath therapy have been found to have positive effects on pain, hand muscle strength, functional status, and QoL in the treatment of hand OA. However, no superiority was observed between the two treatment modalities.

Keywords: Fluidotherapy, grip strength, hand functions, hand osteoarthritis, paraffin.
\end{abstract}

Hand osteoarthritis (OA) is a chronic disease causing decreased quality of life (QoL) due to decreased hand function, loss of hand muscle strength, and pain. ${ }^{1}$

The role of pharmacological treatments in the treatment of $\mathrm{OA}$ is limited. The side effects of medical treatments limit their use in the treatment of $\mathrm{OA}$ since $\mathrm{OA}$ is frequently seen in the elderly population, has a chronic course, and its treatment takes a longer time. ${ }^{2-4}$ Non-pharmacological treatments include patient education, self-management programs, joint protection techniques, exercises, assistive devices, orthoses, and thermal modalities. ${ }^{5-9}$

Hand $\mathrm{OA}$ is a blurred area in evaluating the efficacy of treatment modalities. There are few

Received: March 23, 2020 Accepted: August 09, 2020 Published online: September 28, 2020

Correspondence: Sami Küçükşen, MD. Necmettin Erbakan Üniversitesi Tıp Fakültesi, Fiziksel Tıp ve Rehabilitasyon Anabilim Dalı, 42080 Selçuklu, Konya, Türkiye. Tel: +90 332 - 2237150 e-mail: samikucuksen@hotmail.com

Citation:

Öncel A, Küçükşen S, Ecesoy H, Sodalı E, Yalçın Ş. Comparison of efficacy of fluidotherapy and paraffin bath in hand osteoarthritis: A randomized controlled trial. Arch Rheumatol 2021;36(2):201-209.

@2021 Turkish League Against Rheumatism. All rights reserved.

This is an open access article under the terms of the Creative Commons Attribution-NonCommercial License, which permits use, distribution and reproduction in any medium, provided the original work is properly cited and is not used for commercial purposes (http://creativecommons.org/licenses/by-nc/4.0/). 
randomized controlled trials evaluating the efficacy of different non-pharmacological treatments on hand OA, and most of them are of poor quality. It is difficult to perform a meta-analysis because of the heterogeneous approaches and the absence of standard outcome measures. ${ }^{10-12}$

Although physical therapy modalities are widely used in the treatment of hand $\mathrm{OA}$ in clinical practice, there is no evidence-based data about which modality should be preferred in the treatment of hand OA. Despite the fact that the number of randomized controlled trials investigating the efficacy of non-pharmacological treatments in hand OA cases has increased in recent years, the number of studies investigating physical therapy modalities is very small. These studies have generally investigated the efficacy of the following treatment modalities: exercises, ${ }^{13-15}$ laser treatments, ${ }^{16,17}$ infrared therapy ${ }^{18}$ different mobilization techniques, ${ }^{19,20}$ magnetotherapy, ${ }^{21}$ and balneotherapy. ${ }^{22,23}$

American College of Rheumatology (ACR) recommends the use of thermal modalities in the treatment of hand OA. ${ }^{5,8}$ In 2007, The European League Against Rheumatism (EULAR) recommended the use of heaters such as paraffin and hot pack and ultrasound therapy in the treatment of hand OA, particularly before exercise. ${ }^{7}$ However, the recommendation was deleted in 2018 stating that the use of these treatment modalities was based on expert opinion and extrapolated from hip or knee OA studies. ${ }^{24}$

In in vivo studies, paraffin therapy induces local relaxation of smooth muscles in the arterioles by causing an increase in the temperature up to $7.5^{\circ} \mathrm{C}$ in the joint capsule and muscles. It shows its efficacy by providing vasodilation in peripheral blood vessels, increasing hyperemia and tissue fluid conduction, and accelerating the lymph flow and absorption of the exudate. A limited number of randomized controlled trials have shown its efficacy in patients with hand OA. ${ }^{25,26}$

Fluidotherapy, which provides dry heating, conducts heat to the soft tissues through convection. Heating is provided by synthetic cellulose parts in dry air. Fluidotherapy has been reported to be the most preferred thermal modality after paraffin and ultrasound in the treatment of hand OA cases. ${ }^{27}$ Although it is widely preferred in patients with $\mathrm{OA}$, there is a limited number of studies in the literature showing the efficacy of fluidotherapy in OA patients. Therefore, in this study, we aimed to compare the efficacy of paraffin bath therapy and fluidotherapy on pain, hand muscle strength, functional status, and QoL in patients with hand OA.

\section{PATIENTS AND METHODS}

In this prospective randomized controlled study, 98 patients who applied to Necmettin Erbakan University, Meram Faculty of Medicine, Physical Medicine and Rehabilitation between July 2017 and March 2018 with the complaint of bilateral hand pain were assessed for eligibility. All patients were examined by the same researcher for the diagnosis of primary hand OA according to the ACR criteria. ${ }^{28}$

Exclusion criteria included secondary hand OA due to various diseases such as gout, hemochromatosis, or calcium pyrophosphate deposition disease, rheumatoid arthritis or psoriatic arthritis, malignancy, entrapment neuropathy, diabetic neuropathy or other neurological diseases of the upper extremity, open wound of the hand, chronic infection, palmar tenosynovitis, severe hand injury or surgical operation within the last six months, intraarticular steroid or hyaluronic acid injection into the hand joint within the last six months, or balneotherapy within last six months.

A total of 16 patients were excluded from the study based on the exclusion criteria (nine patients had another rheumatic disease that affected hand functions, four had received balneotherapy in the last six months, and three were diagnosed with neuropathy). Remaining 82 patients were randomly assigned into fluidotherapy or paraffin groups via the sealed envelope method. However, in paraffin group, at the first month control, one patient left the study due to moving out of the city, two patients discontinued the treatment without giving any reason, and at the third month follow-up, two patients developed a local or systemic disease affecting hand function. Finally, a total of 77 patients $(8$ males, 69 females; mean age: $63.1 \pm 10.3$ years; range 39 to 88 years) (36 in paraffin group, 41 in fluidotherapy group) completed the study (Figure 1). The study protocol was approved by the Necmettin Erbakan University, Meram Faculty of Medicine 


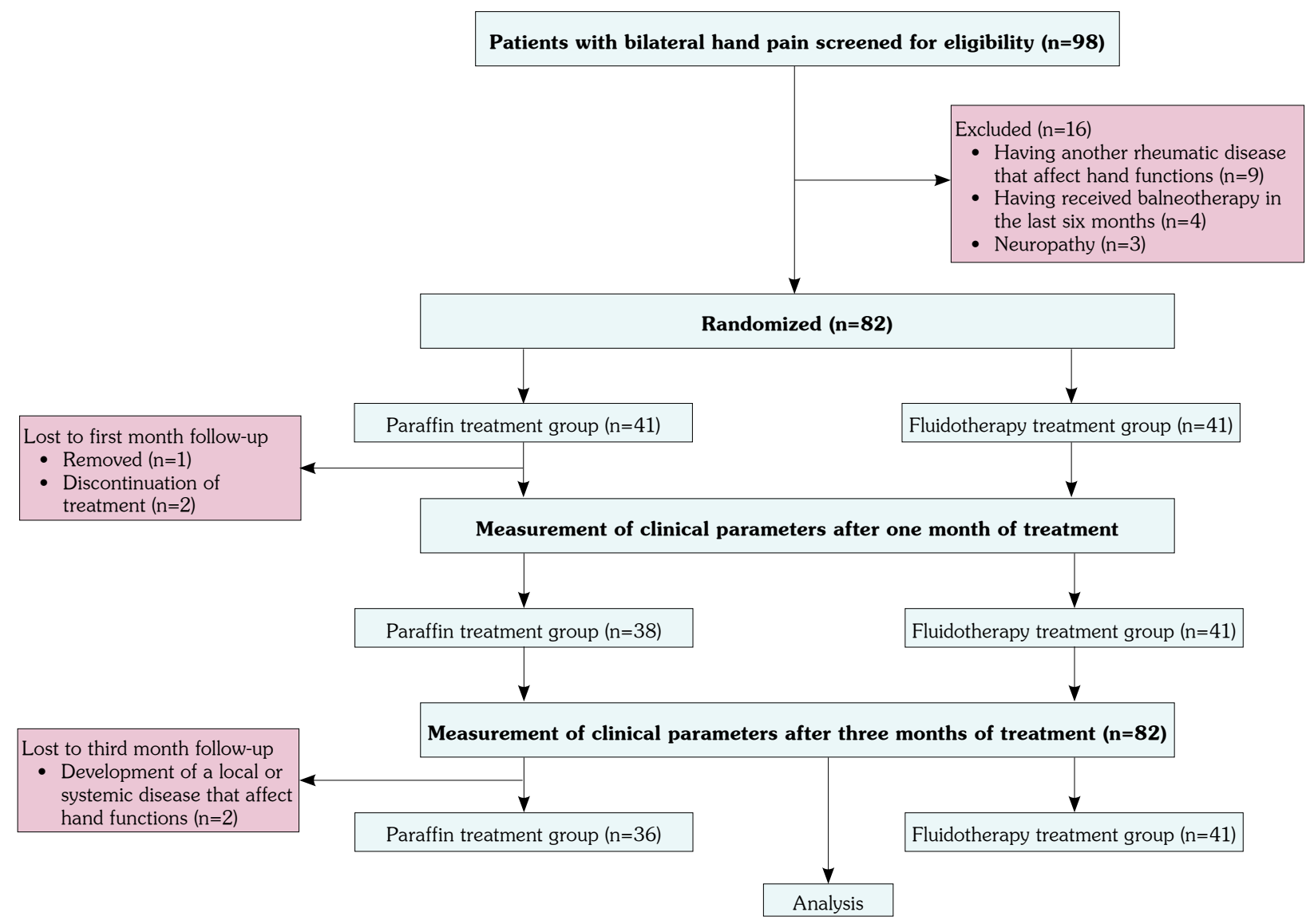

Figure 1. Study design and flow of participants through trial.

Ethics Committee. A written informed consent was obtained from each patient. The study was conducted in accordance with the principles of the Declaration of Helsinki.

Sociodemographic and clinical characteristics of the patients including age, sex, body mass index (BMI), occupation, educational level, duration of disease, frequency of menopause, and duration of menopause were recorded. A researcher blinded to groups evaluated the patients in terms of outcome measures before treatment, immediately after treatment, and three months after treatment. The primary evaluation criteria were pain, hand functions, and QoL. Pain at rest and pain during activities of daily living (ADL) within the last $48 \mathrm{~h}$ was assessed via a $10-\mathrm{cm}$ Visual Analog Scale (VAS). Hand functions were evaluated with Duruöz Hand Index (DHI ${ }^{29}$ whereas gross grip strength was assessed via Jamar dynamometer (J A Preston Corp., New
York, USA) and fine grip strength was measured using pinch meter in three different positions (lateral pinch, tip pinch, and palmar pinch). The 36-Item Short Form (SF-36) ${ }^{30}$ was used to analyze the QoL.

The patients in the paraffin group received paraffin treatment for 14 days, one session per day. During the application, patients dipped their hands into the paraffin bath for 10 times. Their hands were covered with a towel and waited for 20 minutes to preserve the heat. For the treatment, a standard paraffin boiler of $28 \mathrm{~L}$ with an automatic thermostat and a temperature of $53^{\circ} \mathrm{C}$ was used. In the fluidotherapy group, the distal part of the forearm was completely placed inside the device when the patients were in a seated position. This procedure was performed for 14 days, a session (20 min) per day. Chattanooga ${ }^{\circledR}$ FLU115 (Chattanooga Group, Inc., Hixson, TN, USA) was used for fluidotherapy. 


\section{Statistical analysis}

Statistical analysis was performed using the SPSS version 15.0 software (SPSS Inc., Chicago, IL, USA). Descriptive statistics were expressed as number, percentage, mean and standard deviation, median. Visual (histogram and probability plots) and analytical techniques (Kolmogorov-Smirnov, Shapiro-Wilk tests) were used to evaluate whether the variables showed a normal distribution. Dependent t-test and independent $\mathrm{t}$-test were used for the intra- and intergroup comparison of the normally distributed numerical variables, respectively. Wilcoxon signedrank test and Mann-Whitney $U$ test were used for the intra- and intergroup comparison of the not-normally distributed numerical variables, respectively. Chi-square analysis was preferred to compare the nominal data. A $p$ value of $<0.05$ was considered statistically significant in all statistical analyses.

\section{RESULTS}

There was no significant difference between the groups in terms of age, sex, BMI, occupation, and educational status (Table 1). Similarly, there was no significant difference between the groups in terms of VAS score at rest, VAS score during ADL, hand muscle strength, DHI scores, and SF-36 scores before treatment (Table 2).

Findings obtained before, immediately after, and three months after treatment were examined in each group. In the paraffin group, a significant decrease was observed in the VAS scores both at rest and during ADL after treatment compared to the baseline $(p<0.001)$. However, an increase was observed in the VAS score in the third month compared to the VAS score measured immediately after treatment. Despite this, thirdmonth scores were lower than those measured before treatment $(p<0.001)$.

In the fluidotherapy group, a significant decrease was observed in the VAS scores both at rest and during ADL after treatment compared to the baseline $(\mathrm{p}<0.001)$. However, an increase was observed in the VAS score at rest in the third month compared to the VAS score measured immediately after treatment $(p=0.020)$. There was no change in VAS score during ADL in the third month compared to VAS score during ADL measured immediately after treatment $(p=0.538)$. Despite this, third-month VAS scores at rest and

Table 1. Sociodemographic characteristics of patients

\begin{tabular}{|c|c|c|c|c|c|c|c|c|c|c|}
\hline & \multicolumn{3}{|c|}{ Total } & \multicolumn{3}{|c|}{ Paraffin } & \multicolumn{3}{|c|}{ Fluidotherapy } & \multirow[b]{2}{*}{$p^{*}$} \\
\hline & $\mathrm{n}$ & $\%$ & Mean \pm SD & $\mathrm{n}$ & $\%$ & Mean \pm SD & $\mathrm{n}$ & $\%$ & Mean \pm SD & \\
\hline Age (year) & & & $63.1 \pm 10.3$ & & & $61.9 \pm 10.3$ & & & $64.2 \pm 10.3$ & 0.323 \\
\hline Sex & & & & & & & & & & 0.015 \\
\hline Male & 8 & 10.4 & & 7 & 19.4 & & 1 & 2.4 & & \\
\hline Female & 69 & 89.6 & & 29 & 80.6 & & 40 & 97.6 & & \\
\hline Body mass index $\left(\mathrm{kg} / \mathrm{m}^{2}\right)$ & & & $32.0 \pm 5.4$ & & & $31.2 \pm 5.9$ & & & $32.7 \pm 4.9$ & 0.251 \\
\hline Occupation & & & & & & & & & & 0.159 \\
\hline Unemployed & 64 & 83.1 & & 27 & 75.0 & & 37 & 90.2 & & \\
\hline Retired & 10 & 13.0 & & 7 & 19.4 & & 3 & 7.3 & & \\
\hline Worker & 2 & 2.6 & & 2 & 5.6 & & 0 & 0 & & \\
\hline Civil servant & 1 & 1.3 & & 0 & 0 & & 1 & 2.4 & & \\
\hline Education & & & & & & & & & & 0.574 \\
\hline Illiterate & 26 & 33.8 & & 11 & 30.6 & & 15 & 36.6 & & \\
\hline Primary school & 41 & 53.2 & & 20 & 55.6 & & 21 & 51.2 & & \\
\hline High school & 4 & 5.2 & & 1 & 2.8 & & 3 & 7.3 & & \\
\hline University & 6 & 7.8 & & 4 & 11.1 & & 2 & 4.9 & & \\
\hline Disease duration (year) & & & $4.7 \pm 4.6$ & & & $4.6 \pm 5.0$ & & & $4.8 \pm 4.4$ & 0.822 \\
\hline Menopause & 65 & 84.4 & & 27 & 75.0 & & 38 & 92.7 & & 0.056 \\
\hline Duration of menopause (year) & & & $18.8 \pm 11.5$ & & & $18.0 \pm 12.5$ & & & $19.3 \pm 10.8$ & 0.674 \\
\hline
\end{tabular}


Table 2. Clinical parameters of groups

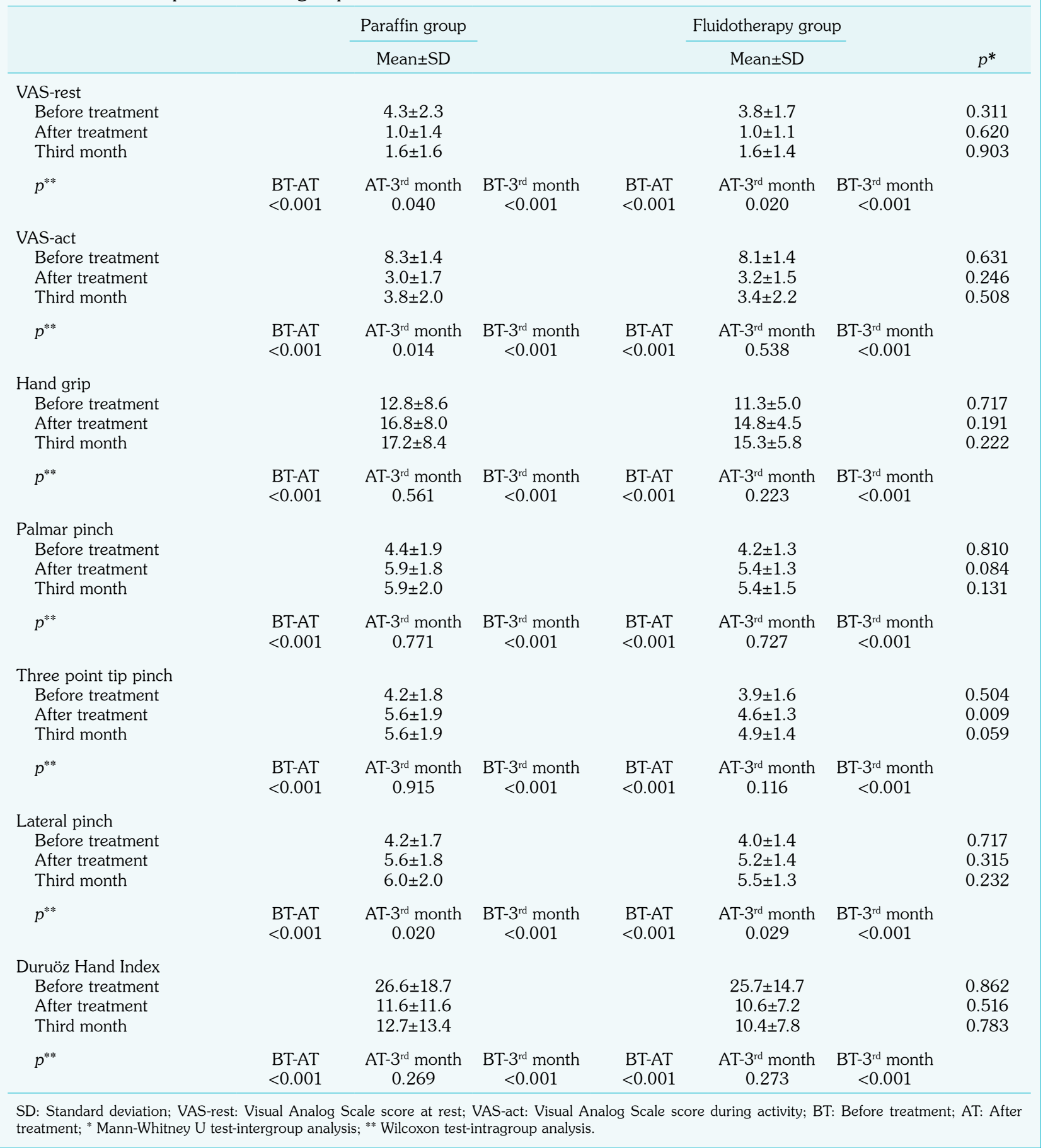

during ADL were lower than those measured before treatment $(p<0.001)$.

There was a significant decrease in the posttreatment DHI scores of both groups compared to the baseline $(p<0.001)$. Statistically significant improvement in DHI scores after the treatment also continued in the third month $(p<0.001)$. However, DHI scores measured immediately after treatment and those measured in the third month were similar. 
Table 3. Intra- and intergroup analysis of 36-item Short Form scores

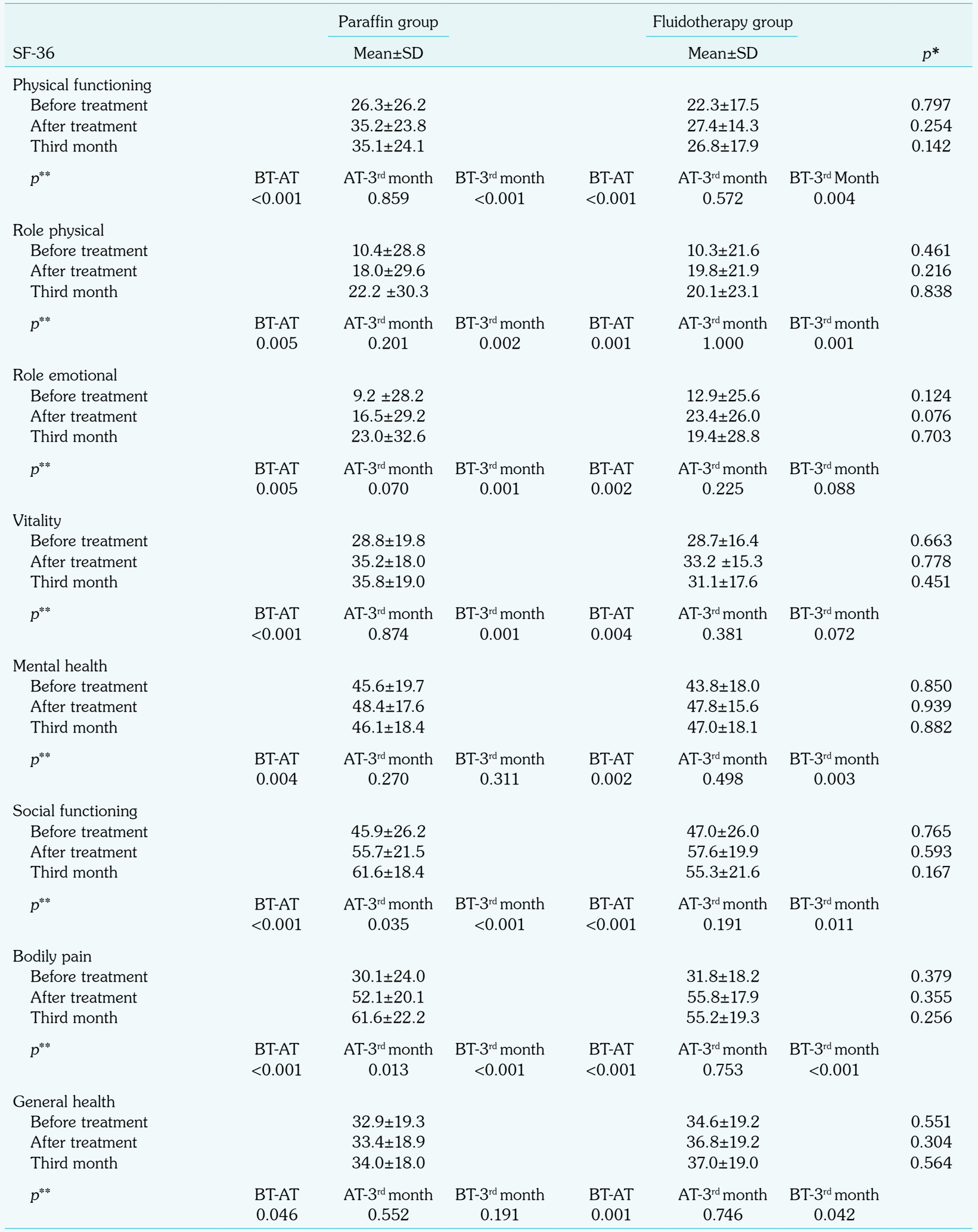

SF-36: 36-Item Short Form; SD: Standard deviation; BT: Before treatment; AT: After treatment; * Mann-Whitney U test-intergroup analysis; ${ }^{* *}$ Wilcoxon testintragroup analysis. 
When the intragroup analysis of gross grip strength was examined, a significant improvement was observed in gross grip, palmar pinch, and tip pinch strengths in both groups after treatment $(p<0001)$. This improvement also continued in the third month $(p<0.001)$. Gross grip, palmar pinch, and tip pinch strengths in the third month were similar to those measured immediately after treatment.

A significant increase was observed in the lateral pinch strength in both groups after treatment compared to the baseline $(p<0.001)$ and in the third month compared to the pinch strength measured immediately after treatment $(p=0.020$ in paraffin group and $p=0.029$ in fluidotherapy group).

There was a significant increase in the SF-36 subscale scores (physical functioning, role limitations due to physical health problems, role limitations due to emotional problems, energy/vitality, mental health, social functioning, bodily pain, and general health perceptions) of both groups after treatment compared to the pretreatment scores. The increase in social functioning $(p=0.035)$ and bodily pain $(p=0.013)$ subscores in the paraffin group continued in the third month. However, there was no difference in other SF-36 subscale scores after treatment and in the third month. In the fluidotherapy group, there was no difference in the SF-36 subscale scores after treatment and in the third month. Mental health $(p=0.311)$ and general health perception $(p=0.191)$ scores in the paraffin group and role limitations due to emotional problems $(p=0.088)$ and energy/vitality $(p=0.072)$ scores in the fluidotherapy group returned to pretreatment values in the third month. Other SF-36 subscale scores remained higher than the pretreatment values in the third month.

There was no difference between the paraffin and fluidotherapy groups in terms of VAS scores at rest and during ADL, DHI scores, SF-36 subscales, gross grip strength, palmar pinch and lateral pinch strength measured before, immediately after, and three months after treatment. The tip pinch strengths of the treatment groups measured before treatment $(p=0.504)$ were similar; however, tip pinch strength was higher in the paraffin group after treatment $(p=0.009)$. Tip pinch strengths of the treatment groups were similar in the third month (Table 3).

\section{DISCUSSION}

In this study, positive outcomes have been obtained after treatment in both paraffin and fluidotherapy groups in terms of pain at rest and during activity, hand functions, hand muscle strength, and QoL. However, the treatment modalities were not found to be superior to each other.

In the literature, there is a limited number of randomized controlled trials on the treatment of hand OA. Most of these studies are weak in terms of methodology. ${ }^{31,32}$ Although pain and function values have been reported in most of the studies in the relevant literature, other outcome measures have been reported in less than $50 \%$ of the studies. ${ }^{10}$ In the present study, hand muscle strength and QoL were evaluated as well as pain and physical function.

The results of the present study are compatible with ACR and 2007 EULAR recommendations suggesting the use of heat application among non-pharmacological treatments in the treatment of hand OA.

Most of the studies have supported our finding that paraffin is effective in hand $\mathrm{OA}$ patients. ${ }^{25,26,33}$ In a study by Myrer et al., ${ }^{26}$ the efficacy of paraffin in patients with hand OA was evaluated and patients were analyzed for pain and hand function. The authors reported improvement in pain and hand function after paraffin treatment. The present study has confirmed that the paraffin bath therapy has provided successful outcomes in patients with hand OA in terms of pain, hand functions, hand muscle strength, and QoL. In a randomized controlled trial carried out by Dilek et al. ${ }^{25}$ in Turkey involving 56 patients with hand OA, the efficacy of paraffin was compared with the control group. Patients were compared with the control group in terms of pain at rest and during ADL, Australian Canadian Osteoarthritis Hand Index, the Dreiser Functional Index, range of motion, and hand muscle strength. The authors reported a significant improvement in terms of the reduction in pain during rest and ADL, gross 
grip, lateral pinch, and tip pinch strengths in the paraffin group compared to the control group. The improvements achieved have been reported to continue until the third month.

In contrast to paraffin treatment, studies and evidence-based data on fluidotherapy are very limited. There are no randomized controlled trials evaluating the efficacy of fluidotherapy on pain, functionality, QoL, and hand muscle strength in patients with hand OA. Most of the data on fluidotherapy were obtained in non-OA diseases. Therefore, our study has provided important data about the efficacy of fluidotherapy in the treatment of hand OA.

Apart from OA, fluidotherapy has also been proven to be effective in reducing hand edema and examining the effect on nerve conduction velocities in carpal tunnel syndrome and stroke patients, and in warming the hypothermic patients. ${ }^{34-36}$ In light of these findings, fluidotherapy may be preferred in patients with $\mathrm{OA}$, while further studies are needed due to the limited number of studies in this field.

This study has some limitations. Firstly, a three-month follow-up period was selected and our results, therefore, reflect the short-term findings. However, a three-month follow-up period had been selected in the majority of prospective studies. Secondly, radiographic evaluation could not be performed due to the short follow-up period. Another limitation was that we did not specify the number and localization of the symptomatic joints. On the other hand, this is the first study in the literature comparing the efficacy of fluidotherapy and paraffin bath therapy in patients with hand OA. Therefore, this is a pilot study and there is a need for further studies to confirm our findings.

In conclusion, fluidotherapy is a good alternative to commonly performed paraffin therapy in terms of pain, hand functions, QoL, and hand muscle strength and it has the same level of efficacy as paraffin therapy in the treatment of hand OA. With these findings, we think that EULAR should reconsider its recommendation by including the paraffin bath therapy and fluidotherapy as a method for the management of hand $\mathrm{OA}$.

\section{Declaration of conflicting interests}

The authors declared no conflicts of interest with respect to the authorship and/or publication of this article.

\section{Funding}

The authors received no financial support for the research and/or authorship of this article.

\section{REFERENCES}

1. Marshall M, Watt FE, Vincent TL, Dziedzic K. Hand osteoarthritis: clinical phenotypes, molecular mechanisms and disease management. Nat Rev Rheumatol 2018;14:641-56.

2. Kloppenburg M, Kwok WY. Hand osteoarthritis-a heterogeneous disorder. Nat Rev Rheumatol 2011;8:22-31.

3. Michon M, Maheu E, Berenbaum F. Assessing healthrelated quality of life in hand osteoarthritis: a literature review. Ann Rheum Dis 2011;70:921-8.

4. Slatkowsky-Christensen $\mathrm{B}$, Mowinckel $\mathrm{P}$, Loge $\mathrm{JH}$, Kvien TK. Health-related quality of life in women with symptomatic hand osteoarthritis: a comparison with rheumatoid arthritis patients, healthy controls, and normative data. Arthritis Rheum 2007;57:1404-9.

5. Hochberg MC, Altman RD, April KT, Benkhalti M, Guyatt G, McGowan J, et al. American College of Rheumatology 2012 recommendations for the use of nonpharmacologic and pharmacologic therapies in osteoarthritis of the hand, hip, and knee. Arthritis Care Res (Hoboken) 2012;64:465-74.

6. National Institute for Health and Clinical Excellence (UK); 2014 Feb. Osteoarthritis. The care and management in adults. Available at: https://www. nice.org.uk/guidance/cg177

7. Zhang W, Doherty M, Leeb BF, Alekseeva L, Arden NK, Bijlsma JW, et al. EULAR evidence based recommendations for the management of hand osteoarthritis: report of a Task Force of the EULAR Standing Committee for International Clinical Studies Including Therapeutics (ESCISIT). Ann Rheum Dis 2007;66:377-88.

8. Kolasinski SL, Neogi T, Hochberg MC, Oatis C, Guyatt G, Block J, et al. 2019 American College of Rheumatology/Arthritis Foundation Guideline for the Management of Osteoarthritis of the Hand, Hip, and Knee. Arthritis Rheumatol 2020;72:220-33.

9. Rillo $\mathrm{O}$, Riera $\mathrm{H}$, Acosta $\mathrm{C}$, Liendo $\mathrm{V}$, Bolaños $\mathrm{J}$, Monterola L, et al. PANLAR Consensus Recommendations for the Management in Osteoarthritis of Hand, Hip, and Knee. J Clin Rheumatol 2016;22:345-54.

10. Lue S, Koppikar S, Shaikh K, Mahendira D, Towheed TE. Systematic review of non-surgical therapies for 
osteoarthritis of the hand: an update. Osteoarthritis Cartilage 2017;25:1379-89.

11. Mahendira D, Towheed TE. Systematic review of nonsurgical therapies for osteoarthritis of the hand: an update. Osteoarthritis Cartilage 2009;17:1263-8.

12. Valdes K, Marik T. A systematic review of conservative interventions for osteoarthritis of the hand. J Hand Ther 2010;23:334-50.

13. Davenport BJ, Jansen V, Yeandle N. Pilot randomized controlled trial comparing specific dynamic stability exercises with general exercises for thumb carpometacarpal joint osteoarthritis. Hand Therapy 2012;17:60-7.

14. Hennig T, Hæehre L, Hornburg VT, Mowinckel P, Norli ES, Kjeken I. Effect of home-based hand exercises in women with hand osteoarthritis: a randomised controlled trial. Ann Rheum Dis 2015;74:1501-8.

15. Østerås N, Hagen KB, Grotle M, Sand-Svartrud AL, Mowinckel P, Kjeken I. Limited effects of exercises in people with hand osteoarthritis: results from a randomized controlled trial. Osteoarthritis Cartilage 2014;22:1224-33.

16. Brosseau L, Wells G, Marchand S, Gaboury I, Stokes $\mathrm{B}$, Morin $\mathrm{M}$, et al. Randomized controlled trial on low level laser therapy (LLLT) in the treatment of osteoarthritis (OA) of the hand. Lasers Surg Med 2005;36:210-9.

17. Paolillo AR, Paolillo FR, João JP, João HA, Bagnato VS. Synergic effects of ultrasound and laser on the pain relief in women with hand osteoarthritis. Lasers Med Sci 2015;30:279-86.

18. Stange-Rezende L, Stamm TA, Schiffert T, Sahinbegovic E, Gaiger A, Smolen J, et al. Clinical study on the effect of infrared radiation of a tiled stove on patients with hand osteoarthritis. Scand J Rheumatol 2006;35:476-80.

19. Villafañe JH, Silva GB, Fernandez-Carnero J. Effect of thumb joint mobilization on pressure pain threshold in elderly patients with thumb carpometacarpal osteoarthritis. J Manipulative Physiol Ther 2012;35:110-20.

20. Villafañe JH, Bishop MD, Fernández-de-Las-Peñas C, Langford D. Radial nerve mobilisation had bilateral sensory effects in people with thumb carpometacarpal osteoarthritis: a randomised trial. $\mathrm{J}$ Physiother 2013;59:25-30.

21. Kanat E, Alp A, Yurtkuran M. Magnetotherapy in hand osteoarthritis: a pilot trial. Complement Ther Med 2013;21:603-8.

22. Horváth K, Kulisch Á, Németh A, Bender T. Evaluation of the effect of balneotherapy in patients with osteoarthritis of the hands: a randomized controlled single-blind follow-up study. Clin Rehabil 2012;26:431-41.

23. Kovács C, Pecze M, Tihanyi Á, Kovács L, Balogh $\mathrm{S}$, Bender T. The effect of sulphurous water in patients with osteoarthritis of hand. Double-blind, randomized, controlled follow-up study. Clin
Rheumatol 2012;31:1437-42.

24. Kloppenburg M, Kroon FP, Blanco FJ, Doherty M, Dziedzic KS, Greibrokk E, et al. 2018 update of the EULAR recommendations for the management of hand osteoarthritis. Ann Rheum Dis 2019;78:16-24.

25. Dilek B, Gözüm M, Şahin E, Baydar M, Ergör G, El $\mathrm{O}$, et al. Efficacy of paraffin bath therapy in hand osteoarthritis: a single-blinded randomized controlled trial. Arch Phys Med Rehabil 2013;94:642-9.

26. Myrer JW, Johnson AW, Mitchell UH, Measom GJ, Fellingham GW. Topical analgesic added to paraffin enhances paraffin bath treatment of individuals with hand osteoarthritis. Disabil Rehabil 2011;33:467-74.

27. O'Brien VH, McGaha JL. Current practice patterns in conservative thumb CMC joint care: survey results. J Hand Ther 2014;27:14-22.

28. Altman R, Alarcón G, Appelrouth D, Bloch D, Borenstein D, Brandt $\mathrm{K}$, et al. The American College of Rheumatology criteria for the classification and reporting of osteoarthritis of the hand. Arthritis Rheum 1990;33:1601-10.

29. Duruöz MT, Poiraudeau S, Fermanian J, Menkes CJ, Amor B, Dougados M, et al. Development and validation of a rheumatoid hand functional disability scale that assesses functional handicap. J Rheumatol 1996;23:1167-72.

30. Ware JE Jr, Sherbourne CD. The MOS 36-item shortform health survey (SF-36). I. Conceptual framework and item selection. Med Care 1992;30:473-83.

31. Maheu E, Altman RD, Bloch DA, Doherty M, Hochberg M, Mannoni A, et al. Design and conduct of clinical trials in patients with osteoarthritis of the hand: recommendations from a task force of the Osteoarthritis Research Society International. Osteoarthritis Cartilage 2006;14:303-22.

32. Kloppenburg M, Maheu E, Kraus VB, Cicuttini F, Doherty M, Dreiser RL, et al. OARSI Clinical Trials Recommendations: Design and conduct of clinical trials for hand osteoarthritis. Osteoarthritis Cartilage 2015;23:772-86.

33. Uçar D, Paker N, Buğdayci DS, Yalçinkaya EY. Semptomatik el osteoartriti olan kadınlarda girdap ve parafin tedavilerinin etkinliklerinin karşılaştırması. Türk Fiz Tip Rehab Derg 2011;57:124-7.

34. Han SW, Lee MS. The effect of fluidotherapy on hand dexterity and activities of daily living in patients with edema on stroke. J Phys Ther Sci 2017;29:2180-3.

35. Kelly R, Beehn C, Hansford A, Westphal KA, Halle JS, Greathouse DG. Effect of fluidotherapy on superficial radial nerve conduction and skin temperature. J Orthop Sports Phys Ther 2005;35:16-23.

36. Kumar P, McDonald GK, Chitkara R, Steinman AM, Gardiner PF, Giesbrecht GG. Comparison of distal limb warming with fluidotherapy and warm water immersion for mild hypothermia rewarming. Wilderness Environ Med 2015;26:406-11. 